\title{
Higher cord blood 25-hydroxyvitamin D concentrations reduce the risk of early childhood eczema: in children with a family history of allergic disease
}

\author{
Debra Jane Palmer ${ }^{1,2^{*}}$, Thomas R. Sullivan ${ }^{3}$, Clark M. Skeaff ${ }^{4}$, Lisa G. Smithers ${ }^{3}$, Maria Makrides ${ }^{1,5,6}$
}

and on behalf of the DOMInO Allergy Follow-up Team

\begin{abstract}
Background: In recent years the role of vitamin D status in early life on the development of allergic disease has generated much interest. The aim of this study was to determine whether cord blood vitamin D concentrations were associated with risk of early childhood allergic disease.

Methods: Measurements of cord blood 25-hydroxyvitamin D [25(OH)D] concentrations were available in 270 mother-child pairs who were participating in the allergy follow-up $(n=706)$ of the Docosahexaenoic Acid to Optimise Mother Infant Outcome randomised controlled trial. All of the children had a hereditary risk of allergic disease. The diagnosis of allergic disease was made during medical assessments at 1 and 3 years of age.

Results: The mean (standard deviation) standardised cord blood 25(OH)D concentration was $57.0(24.1) \mathrm{nmol} / \mathrm{L}$. The cumulative incidence of eczema to 3 years of age, $n=101 / 250$ (40 \%) was associated with standardised cord blood $25(\mathrm{OH}) \mathrm{D}$ concentration, with a $10 \mathrm{nmol} / \mathrm{L}$ rise in $25(\mathrm{OH}) \mathrm{D}$ concentration reducing the risk of eczema by $8 \%$ (relative risk $0.92,95 \%$ confidence interval $0.86-0.97 ; P=0.005$ ). This association was stronger at 1 year of age, when a $10 \mathrm{nmol} / \mathrm{L}$ rise in standardised cord blood $25(\mathrm{OH}) \mathrm{D}$ concentration reduced the risk of eczema by $12 \%$ (relative risk $0.88,95 \%$ confidence interval $0.81-0.96 ; P=0.002)$. No associations between cord blood 25(OH)D concentrations and development of allergic sensitisation, allergic rhinitis or asthma in early childhood were found.
\end{abstract}

Conclusion: In children with a family history of allergic disease, a higher cord blood 25(OH)D concentration appears to be associated with reduced risk of eczema in early childhood.

Trial registration: Australian New Zealand Clinical Trials Registry ACTRN12610000735055 (DOMInO trial: ACTRN12605000569606).

Keywords: Allergy prevention, Cord blood, Eczema, Pregnancy, Vitamin D

\section{Background}

Vitamin D is well known for its role in bone metabolism, however in recent years, the effects of vitamin D on immune function and the development of allergic disease has generated much interest. Some epidemiological studies

\footnotetext{
* Correspondence: debbie.palmer@uwa.edu.au

'Women's \& Children's Health Research Institute, University of Adelaide,

North Adelaide, SA 5006, Australia

${ }^{2}$ School of Paediatrics and Child Health, University of Western Australia,

Subiaco, WA 6008, Australia

Full list of author information is available at the end of the article
}

have shown that lower maternal vitamin D dietary intakes during pregnancy increases the risk of allergic disease; atopic dermatitis/eczema [1], food allergen sensitisation [2], asthma [3] and allergic rhinitis [3] in the offspring. Studies to date investigating the associations between objective measures of maternal vitamin D status during pregnancy and allergic disease outcomes in childhood have been limited. Three recent studies [4-6] have found that higher cord blood vitamin D concentrations were protective against the development of early childhood atopic dermatitis/eczema, respiratory tract infection and wheezing, 
but not asthma or allergic rhinitis. However childhood allergy outcomes in these three studies [4-6] relied on parent reported history of doctor diagnosed outcomes rather than direct standardised medical practitioner clinical assessments.

The best indicator of vitamin D status is considered to be the measurement of serum 25-hydroxyvitamin $\mathrm{D}(25(\mathrm{OH}) \mathrm{D})$, which is the most abundant and stable vitamin D metabolite [7]. Serum $25(\mathrm{OH}) \mathrm{D}$ concentrations reflect vitamin $\mathrm{D}$ produced from sunlight exposure and intake from foods and supplements. It has been well established that serum $25(\mathrm{OH}) \mathrm{D}$ concentrations $\geq 50 \mathrm{nmol} /$ $\mathrm{L}$ facilitate optimal bone health (calcitropic function of vitamin D) [8]. However in recent years there has been much discussion about the ideal serum 25(OH)D concentrations needed for other health outcomes, with suggestions [9] that concentrations $\geq 75 \mathrm{nmol} / \mathrm{L}$ may be needed for optimal immune function and for reducing the risk of allergic disease. During pregnancy, the fetus is exposed to vitamin D through the cord blood supply and the ability of $25(\mathrm{OH}) \mathrm{D}$ to cross the placenta [10]. Cord blood 25(OH)D concentrations are highly correlated with infant $[11,12]$ and maternal serum 25(OH)D concentrations [11, 12], although they are usually lower compared with maternal concentrations [13-15].

This paper reports the associations between cord blood 25(OH)D concentrations and standardised clinically assessed allergic disease outcomes to 3 years of age in children with a family history of allergic disease, whose mothers participated in a double-blinded, multi-centre randomised controlled trial of omega-3 long-chain polyunsaturated fatty acids supplementation in pregnancy [16-18].

\section{Methods}

\section{Subjects and study design}

Children $(n=706)$ who had a mother, father or sibling with a history of medically diagnosed allergic disease, and whose mothers were participants in the Docosahexaenoic Acid (DHA) to Optimise Mother Infant Outcome (DOMInO) Trial [16], participated in the allergy followup study of the DOMInO Trial $[17,18]$. Briefly, in the DOMInO trial women allocated to the omega-3 long chain polyunsaturated fatty acid group were asked to consume three $500 \mathrm{mg}$ capsules of fish oil concentrate, providing $800 \mathrm{mg}$ of DHA and $100 \mathrm{mg}$ of eicosapentaenoic acid (EPA). Women in the control group were asked to take three $500 \mathrm{mg}$ vegetable oil capsules without omega-3 long chain polyunsaturated fatty acids daily. Neither of these capsules (intervention or control group) contained vitamin D. Women took capsules from 21 weeks' gestation until delivery. Among the 706 child participants in the allergy follow-up study, measurements of cord blood $25(\mathrm{OH}) \mathrm{D}$ concentrations were available in 270 mother- child pairs. Approval for this study was granted by the Human Research Ethics Committees of the Women's and Children's Hospital and Flinders Medical Centre, Adelaide, Australia.

\section{Measurement of cord blood 25(OH)D concentration}

Samples of umbilical cord blood were collected at birth. Plasma was separated from whole blood by centrifugation and immediately stored at $-20{ }^{\circ} \mathrm{C}$. Samples were shipped to the Steroid and Immunobiochemistry Laboratory (Christchurch, New Zealand) on dry ice. Analysis of $25(\mathrm{OH}) \mathrm{D}$ was conducted using a liquid chromatographytandem mass spectroscopy (LC-MS/MS) method [19]. Accuracy of the method was assessed using Standard Reference Material ${ }^{\circ} 972$ from the National Institute of Standards and Technology (NIST). We determined 25(OH)D3 concentrations in levels 1, 2, and 3 of the Standard Reference Material $^{\circ} 972$ to be $60 \mathrm{nmo} / \mathrm{L}, 30 \mathrm{nmo} / \mathrm{L}$, and $47 \mathrm{nmol} / \mathrm{L}$, respectively, compared with the NIST Certified Concentration Values of $60 \mathrm{nmol} / \mathrm{L}, 31 \mathrm{nmol} / \mathrm{L}$ and $46 \mathrm{nmol} / \mathrm{L}$, respectively. The precision of the method was $6-7 \%$ and was established by repeat $(n=16)$ measurements of three control serum samples 25(OH)D status with concentrations of $23 \mathrm{nmol} / \mathrm{L}, 59 \mathrm{nmol} / \mathrm{L}$ and $107 \mathrm{nmol} / \mathrm{L}$. 25(OH)D concentrations are presented as $\mathrm{nmol} / \mathrm{L}$.

\section{Early childhood allergic disease outcome assessments and definitions}

Children participating in the allergy follow-up of the DOMInO Trial attended a medical review appointment at 1 and 3 years of age $[17,18]$. Allergic sensitisation was defined as a positive skin prick test (weal $\geq 3 \mathrm{~mm}$ above negative control) to at least one of the food allergens (hens' egg, cows' milk, wheat, tuna, peanut, cashew nut and sesame seed) or aeroallergens (ryegrass pollen, olive tree pollen, Alternaria tenuis, cat hair and house dust mites -Dermatophagoides pteronyssinus and Dermatophagoides farinae) assessed. Eczema was defined as the presence of eczema, criteria according to Hanifin and Rajka [20], on medical review or a history of an itchy rash distributed to the facial, flexural, or extensor surface of the skin that had followed a fluctuating or chronic course. IgE-associated food allergy was defined as a history of ingestion of a food with immediate reaction $(<60 \mathrm{~min})$, including skin rash (hives, rash, or swelling) with or without respiratory symptoms (cough, wheeze, stridor), gastrointestinal symptoms (abdominal pain, vomiting, loose stools), or cardiovascular symptoms (collapse), coupled with sensitisation to the implicated food. Asthma was defined as a history of 3 or more episodes of wheeze with the episodes less than 6 weeks apart and/or daily use of asthma medication. Allergic rhinitis was defined as a history of sneezing, or a runny, or blocked nose accompanied by itchy-watery eyes when there have not been symptoms to suggest an upper respiratory tract 
infection. Respiratory tract infections were defined as a parent reported history of medically diagnosed bronchiolitis or Respiratory Syncytial Virus.

\section{Statistical methods}

$25(\mathrm{OH}) \mathrm{D}$ concentrations were standardised to account for variability in cord blood $25(\mathrm{OH}) \mathrm{D}$ by month of birth. Firstly, an overall weighted mean $25(\mathrm{OH}) \mathrm{D}$ concentration was calculated by weighting individual measurements by the inverse of the total number of measurements in the corresponding month (to account for variation in the number of observations in different months). Secondly, the residuals from a regression model of $25(\mathrm{OH}) \mathrm{D}$ on month (treated as a categorical variable) were added to the overall mean $25(\mathrm{OH}) \mathrm{D}$ concentration to create standardised 25(OH)D concentrations. A similar approach was used by Jenab et al. [21].

For all allergy outcomes, log binomial regression models were used to estimate the effect of a $10 \mathrm{nmol} / \mathrm{L}$ increase in standardised $25(\mathrm{OH}) \mathrm{D}$ on the risk of allergy. All associations were described using relative risks with $95 \%$ confidence intervals. Statistical models were adjusted for the following potential confounders; DHA treatment group, parity, sex and maternal smoking during or leading up to pregnancy. The confounders were determined a priori based on previous research showing they are commonly associated with the development of atopic disease [22]. To avoid over-fitting statistical models to outcomes with relatively low incidence, only a limited number of potential confounders were considered prior to analysis. For outcomes where it was not possible to achieve model convergence with adjustment for covariates, results of unadjusted models are presented. Since data were obtained from a randomised trial, effect modification of $25(\mathrm{OH}) \mathrm{D}$ by DHA treatment group was also investigated by adding interaction effects to statistical models. Checks were performed to ensure adequate model fit throughout, with modified Hosmer-Lemeshow tests suggesting that the inclusion of standardised $25(\mathrm{OH}) \mathrm{D}$ as a continuous predictor was reasonable for all the allergy outcomes considered. Statistical significance was assessed at the two sided $P<0.05$ level. All analyses were performed using SAS version 9.3.

\section{Results}

The sample of 270 mother-child pairs with available measurements of cord blood $25(\mathrm{OH}) \mathrm{D}$ concentrations were representative of the overall allergy follow-up study population (see Table 1).

\section{Vitamin D}

The mean (SD) raw cord blood 25(OH)D concentration was $55.9(28.4) \mathrm{nmol} / \mathrm{L}$ and the mean (SD) standardised 25(OH)D concentration was $57.0(24.1) \mathrm{nmol} / \mathrm{L}$. The distribution of cord blood standardised 25(OH)D concentrations are displayed in Fig. 1. Characteristics of the participants and standardised $25(\mathrm{OH}) \mathrm{D}$ concentrations are shown in Table 2. Standardised 25(OH)D concentrations were higher for Caucasian mothers $(n=256)$ with mean (SD) of $58.1(24.1) \mathrm{nmol} / \mathrm{L}$ compared to non-Caucasian mothers $(n=14)$ with mean (SD) of $37.8(14.7) \mathrm{nmol} / \mathrm{L}, P=0.002$. For other participant characteristics that may potentially play a role in allergic disease development, DHA supplementation, maternal smoking, parity and infant sex, the standardised 25(OH)D concentrations did not differ between groups.

\section{Early childhood allergic disease outcomes}

Overall the cumulative incidence of any allergic disease (eczema, IgE-mediated food allergy, allergic rhinitis and/

Table 1 Comparison of baseline characteristics between those with cord blood vitamin D (25 (OH) D) concentration results and total allergy follow-up cohort

\begin{tabular}{lll}
\hline Characteristic $^{\prime}$ & Vitamin D Cohort $(n=270)$ & Total Cohort $(n=706)$ \\
\hline${\text { Mother's age at trial entry (years) }{ }^{\text {a }}}$ & $28.8(5.6)$ & $29.5(5.7)$ \\
Race - Caucasian & $256(94.8)$ & $672(95.2)$ \\
Mother completed secondary education & $171(63.3)$ & $454(64.3)$ \\
Mother smoked during or leading up to pregnancy & $73(27.0)$ & $205(29.0)$ \\
Primiparous & $110(40.7)$ & $281(39.8)$ \\
Maternal history of allergic disease & $182(67.4)$ & $493(69.8)$ \\
Dual parental history of allergic disease & $72(26.7)$ & $206(29.2)$ \\
Infant sex (male) & $129(47.8)$ & $337(47.7)$ \\
Treatment group & & $368(52.1)$ \\
$\quad$ DHA & $130(48.1)$ & $338(47.9)$ \\
Control & $140(51.9)$ & 3 \\
\hline
\end{tabular}

Values are numbers (percentages) unless indicated otherwise

DHA Docosahexaenoic acid

${ }^{\mathrm{a}}$ Mean $( \pm \mathrm{SD})$ 


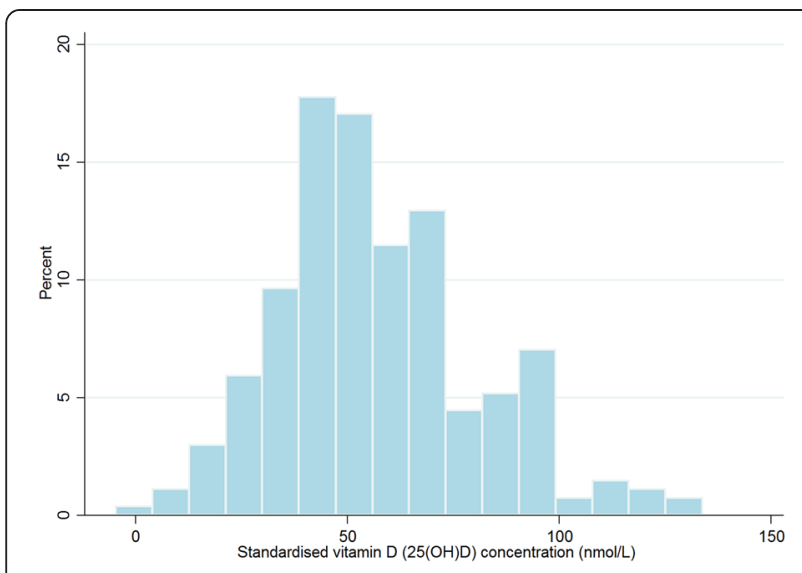

Fig. 1 The distribution of standardised cord blood 25(OH)D concentrations

or asthma) by 3 years of age was $57 \%(137 / 240)$ in this cohort (with a family history of allergic disease). Consistent with the usual pattern of expression of the allergic phenotype, eczema was the most common allergic disease in the first three years of life [23], with a cumulative incidence of $40 \%(101 / 250)$.

There was no evidence for effect measure modification by DHA treatment group in any of the allergic disease outcomes, so interaction effects were not included in the final models. The risk of eczema at 1 year of age decreased as cord blood $25(\mathrm{OH}) \mathrm{D}$ concentration increased; a $10 \mathrm{nmol} / \mathrm{L}$ rise in standardised cord blood $25(\mathrm{OH}) \mathrm{D}$ concentration was associated with a $12 \%$ reduction in risk (relative risk 0.88, $95 \%$ confidence interval $0.81-0.96 ; P=0.002$ (Table 3 ). The cumulative incidence of eczema to 3 years of age was also associated with cord blood 25(OH)D concentration, with a $10 \mathrm{nmol} /$ $\mathrm{L}$ rise in standardised cord blood $25(\mathrm{OH}) \mathrm{D}$ concentration reducing the risk by $8 \%$ (relative risk 0.92, $95 \%$ confidence interval $0.86-0.97 ; P=0.005)$. A similar relationship was observed for eczema at 3 years of age, however the association did not reach statistical significance (Table 3).

The cumulative incidence of eczema with sensitisation by 3 years of age was also associated with cord blood $25(\mathrm{OH}) \mathrm{D}$ concentration, with a $10 \mathrm{nmol} / \mathrm{L}$ rise in standardised cord blood $25(\mathrm{OH}) \mathrm{D}$ concentration reducing the risk by $17 \%$ (relative risk 0.83, $95 \%$ confidence interval $0.72-0.96 ; P=0.01)$. We also observed a reduction in the risk, which did not reach statistical significance, for eczema with sensitisation at 1 year of age and at 3 years of age (Table 3 ).

Medical diagnosis of IgE-mediated food allergy at 1 year of age was uncommon in this cohort, only being identified in $4 / 260(1.5 \%)$ children. The risk of IgEmediated food allergy at 1 year of age (but not at 3 years of age) also decreased as cord blood 25(OH)D concentration increased (Table 3). No associations between cord blood 25(OH)D concentrations and risk of development of allergic sensitisation, allergic rhinitis, asthma or respiratory tract infections in early childhood were found (Table 3).

In exploratory analyses, we examined whether the effect of standardised vitamin D on the allergic disease outcomes was modified by mother's smoking status, cat ownership or dog ownership. As the majority of the participants were breastfed and of Caucasian race, we did not examine effect modification by breastfeeding status or race. There was evidence that the effect of standardised vitamin $\mathrm{D}$ on the cumulative incidence of

Table 2 Characteristics of participants and standardised vitamin D (25OH) D) concentrations

\begin{tabular}{|c|c|c|c|c|c|c|}
\hline Characteristic & $25(\mathrm{OH}) \mathrm{D} \mathrm{nmol} / \mathrm{L}^{\mathrm{a}}$ & $N$ & $<25 \mathrm{nmol} / \mathrm{L}$ & $25-49.9 \mathrm{nmol} / \mathrm{L}$ & $50-74.9 \mathrm{nmol} / \mathrm{L}$ & $\geq 75 \mathrm{nmol} / \mathrm{L}$ \\
\hline Total cohort & $57.0 \pm 24.1$ & $270(100)$ & $19(7.0)$ & $97(35.9)$ & $103(38.2)$ & $51(18.9)$ \\
\hline \multicolumn{7}{|c|}{ Treatment group } \\
\hline Control & $56.9 \pm 24.5$ & $140(51.9)$ & $11(7.9)$ & $47(33.6)$ & $55(39.3)$ & $27(19.3)$ \\
\hline $\mathrm{DHA}$ & $57.2 \pm 23.8$ & $130(48.1)$ & $8(6.2)$ & $50(38.5)$ & $48(36.9)$ & $24(18.5)$ \\
\hline \multicolumn{7}{|c|}{ Mother smoked during or leading up to pregnancy } \\
\hline Yes & $54.7 \pm 21.7$ & $73(27.0)$ & $6(8.2)$ & $28(38.9)$ & $28(38.9)$ & $11(15.1)$ \\
\hline No & $57.9 \pm 24.9$ & $197(73.0)$ & $13(6.6)$ & $69(35.0)$ & $75(38.1)$ & $40(20.3)$ \\
\hline \multicolumn{7}{|l|}{ Parity } \\
\hline 0 & $55.4 \pm 25.7$ & $110(40.7)$ & $11(10.0)$ & $40(36.4)$ & $39(35.5)$ & $20(18.2)$ \\
\hline$>=1$ & $58.2 \pm 23.0$ & $160(59.3)$ & $8(5.0)$ & $57(35.6)$ & $64(40.0)$ & $31(19.4)$ \\
\hline \multicolumn{7}{|l|}{ Infant sex } \\
\hline Male & $59.0 \pm 26.0$ & $129(47.8)$ & $7(5.4)$ & $44(34.1)$ & $52(40.3)$ & $26(20.2)$ \\
\hline Female & $55.2 \pm 22.2$ & $141(52.2)$ & $12(8.5)$ & $53(37.6)$ & $51(36.2)$ & $25(17.7)$ \\
\hline
\end{tabular}

Values are numbers (percentages) unless indicated otherwise

DHA Docosahexaenoic acid

${ }^{\mathrm{a}}$ Mean \pm SD all such values 
Table 3 Associations between standardised vitamin D (25 (OH) D) levels and allergic disease outcomes

\begin{tabular}{|c|c|c|c|c|}
\hline Allergic disease outcome & Incidence ${ }^{a}$ & $\begin{array}{l}\text { Unadjusted } \\
\text { RR }^{\mathrm{b}}(95 \% \mathrm{Cl})\end{array}$ & $\begin{array}{l}\text { Adjusted RR } \\
(95 \% \mathrm{Cl})\end{array}$ & $\begin{array}{l}\text { Adjusted }^{c} \\
\text { P Value }\end{array}$ \\
\hline Eczema at 1 year of age & $70 / 265(26.4)$ & $0.89(0.81,0.97)$ & $0.88(0.81,0.96)$ & 0.002 \\
\hline Eczema with sensitisation at 1 year of age & $19 / 265(7.2)$ & $0.85(0.70,1.04)$ & $0.84(0.69,1.01)$ & 0.07 \\
\hline Eczema at 3 years of age & $77 / 247(31.2)$ & $0.94(0.87,1.01)$ & $0.93(0.86,1.01)$ & 0.07 \\
\hline Eczema with sensitisation at 3 years of age & $26 / 244(10.7)$ & $0.87(0.74,1.02)$ & $0.85(0.73,1.00)$ & 0.051 \\
\hline Cumulative incidence of eczema by 3 years of age & $101 / 250(40.4)$ & $0.92(0.86,0.98)$ & $0.92(0.86,0.97)$ & 0.005 \\
\hline Cumulative incidence of eczema with sensitisation by 3 years of age & $30 / 243(12.3)$ & $0.85(0.73,0.98)$ & $0.83(0.72,0.96)$ & 0.01 \\
\hline IgE-mediated food allergy at 1 year of age & $4 / 260(1.5)$ & $0.60(0.41,0.90)$ & - & $0.01^{d}$ \\
\hline IgE-mediated food allergy at 3 years of age & $7 / 229(3.1)$ & $0.78(0.54,1.13)$ & $0.77(0.50,1.17)$ & 0.22 \\
\hline Cumulative incidence IgE-mediated food allergy by 3 years of age & $8 / 228(3.5)$ & $0.80(0.57,1.12)$ & $0.78(0.55,1.11)$ & 0.17 \\
\hline Any sensitisation at 1 year of age & $36 / 260(13.8)$ & $0.95(0.84,1.09)$ & $0.94(0.83,1.07)$ & 0.36 \\
\hline Any sensitisation at 3 years of age & $52 / 229(22.7)$ & $0.96(0.87,1.07)$ & $0.95(0.86,1.05)$ & 0.28 \\
\hline Cumulative incidence any sensitisation by 3 years of age & $66 / 230(28.7)$ & $0.96(0.88,1.05)$ & $0.95(0.87,1.03)$ & 0.23 \\
\hline Cumulative incidence of allergic rhinitis by 3 years of age & $39 / 246(15.9)$ & $0.97(0.86,1.10)$ & $0.98(0.87,1.11)$ & 0.80 \\
\hline Cumulative incidence of allergic rhinitis with sensitisation by 3 years of age & $13 / 245(5.3)$ & $0.95(0.75,1.19)$ & $0.94(0.75,1.18)$ & 0.60 \\
\hline Cumulative incidence of asthma by 3 years of age & $32 / 248(12.9)$ & $1.03(0.91,1.17)$ & $1.03(0.90,1.18)$ & 0.67 \\
\hline Cumulative incidence of asthma with sensitisation by 3 years of age & $5 / 245(2.0)$ & $1.05(0.74,1.48)$ & - & $0.80^{\mathrm{d}}$ \\
\hline Cumulative incidence of any allergic disease by 3 years of age & $137 / 240(57.1)$ & $0.95(0.90,0.99)$ & $0.95(0.90,0.99)$ & 0.02 \\
\hline Cumulative incidence of any allergic disease with sensitisation by 3 years of age & $40 / 228(17.5)$ & $0.88(0.78,1.00)$ & $0.87(0.77,0.98)$ & 0.03 \\
\hline Respiratory tract infections by 1 year of age & $45 / 267(16.9)$ & $1.08(0.98,1.20)$ & $1.07(0.97,1.18)$ & 0.18 \\
\hline Cumulative incidence of respiratory tract infections by 3 years of age & $70 / 250(28.0)$ & $1.03(0.95,1.11)$ & $1.02(0.95,1.10)$ & 0.61 \\
\hline
\end{tabular}

$R R$ Relative risk

a Values are numbers (percentages)

${ }^{b}$ Relative Risk of outcome corresponding to a 10 unit increase in standardised 25(OH)D

c Adjusted for treatment group, parity, gender and maternal smoking during or leading up to pregnancy

d Unadjusted p-value reported due to low incidence of outcome

any sensitisation by 3 years of age was modified by mother's smoking status (interaction $p$-value $=0.03$ ). A $10 \mathrm{nmol} / \mathrm{L}$ increase in standardised cord blood $25(\mathrm{OH})$ concentration was associated with a $9 \%$ reduction in the risk of any sensitisation at 1 or 3 years in children whose mother did not smoke during or leading up to pregnancy $(R R=0.91 ; 95 \%$ CI $0.82,1.00)$. In contrast, for children with a mother that did smoke, a $10 \mathrm{nmol} / \mathrm{L}$ increase in cord blood 25(OH)D concentration was associated with an $11 \%$ increase in the risk of any sensitisation at 1 or 3 years $(R R=1.11 ; 95 \%$ CI $0.96,1.28)$. No evidence of effect modification was found for any other allergic disease outcomes.

\section{Discussion}

Our results of a $10 \mathrm{nmol} / \mathrm{L}$ rise in standardised cord blood 25(OH)D concentration being associated with reduced risk of eczema are consistent with the findings of other observational studies, which have also reported that higher cord blood $25(\mathrm{OH}) \mathrm{D}$ concentrations are associated with decreased risk of eczema $[4,6]$. There have also been recent studies [15, 24, 25] which have found no association with cord blood 25(OH)D concentration and eczema outcomes in early childhood. Interestingly, our study also found that the cumulative incidence of eczema with sensitisation by 3 years of age was also associated with cord blood 25(OH)D concentration. Previous other studies investigating cord blood $25(\mathrm{OH}) \mathrm{D}$ concentrations have not reported results for atopic eczema (eczema with confirmed sensitisation). Other studies have reported food and/or inhalant allergen sensitisation independent of allergic disease outcomes and in accordance with our findings most $[6,24,25]$ have found no association of cord blood 25(OH)D concentration with child sensitisation status. However Rothers et al. [26] in the United States identified a U-shaped relationship with lower $(<50 \mathrm{nmol} / \mathrm{L})$ and higher $(>100 \mathrm{nmol} / \mathrm{L})$ cord blood 25(OH)D concentrations associated with increased inhalant allergen sensitisation.

There are several biological pathways which may account for a beneficial effect of vitamin D in reducing eczema risk. The pathogenesis of eczema involves immune dysregulation, altered epidermal barrier function and inadequate bacterial defence [27] and vitamin D is known to have a regulatory influence on all of these [28]. Thus, vitamin D deficiency in early life is a strong 
candidate for predisposition to eczema. These biological effects are in keeping with observational studies that have indicated a link between vitamin D status and eczema outcomes, including lower serum vitamin D concentrations associated with increased incidence and severity of eczema symptoms [29].

We also found that higher cord blood 25(OH)D concentrations were associated with decreased risk of development of IgE-mediated food allergy in infancy. However this result should be interpreted with caution due to the low incidence of medically diagnosed IgE-mediated food allergy at 1 year of age $(1.5 \%)$ in our cohort. Our incidence was substantially lower than that reported in another recent Australian cohort, where food challenges identified $>10 \%$ of 1 year olds to have IgE-mediated food allergy [30]. The inability to perform food challenges (due to insufficient resources) may explain the lower incidence of IgE-mediated food allergy at 1 year of age in our cohort. In contrast, a cohort study by Weisse et al. [15] found higher maternal blood (34 weeks gestation) as well as cord blood $25(\mathrm{OH}) \mathrm{D}$ concentrations to be associated with increased risk of parent reported doctor diagnosed food allergy, with an incidence of $5.5 \%$ by 2 years of age. Whereas other studies $[6,25]$ have found no association of cord blood 25(OH)D concentrations with the development of food allergy. Interestingly, the Weisse et al. [15] German cohort study was conducted at a higher latitude of $51^{0} \mathrm{~N}$ (compared to our study at $35^{\circ} \mathrm{S}$ ) with lower median (inter-quartile range) cord blood concentration of $27 \mathrm{nmol} / \mathrm{L}(17-43 \mathrm{nmol} / \mathrm{L})$. These lower average cord blood concentrations may have contributed to their contrasting finding with regard to food allergy outcomes and the finding of no association with offspring eczema outcomes.

The pattern of allergic disease is known to differ with age, with the greatest incidence of food allergy and atopic dermatitis/eczema being in the first few years of life, while asthma and allergic rhinitis continue to rise until adulthood. Consistent with the recent findings of other cohort studies, we found no association of cord blood 25(OH)D concentrations with asthma $[4,5,24,26]$ or allergic rhinitis $[4,5,24,26]$ outcomes. We acknowledge that longer term follow-up of these children is needed before this result can be conclusive and we are currently following up the children in our cohort at 6 years of age for allergic disease outcomes.

The strengths of our study include standardised medical assessments of allergic disease outcomes, with high follow up rates of $>95 \%$ at 1 year and $>90 \%$ at 3 years of age. We also calculated and reported standardised cord blood $25(\mathrm{OH}) \mathrm{D}$ concentrations for our results, which is important to adjust for seasonal variability in $25(\mathrm{OH}) \mathrm{D}$ concentrations due to month of birth. We acknowledge that a limitation of our study was that we have not taken blood samples from the children to examine vitamin D status at multiple time-points during early life. It may be that the timing of differential vitamin D status could have variable effects on the development of allergic diseases. A family history of allergic disease in all the participants in our study may reduce the ability to generalize our findings to the whole population, however Biaz et al. [4] who did not select participants based on a family history of allergic disease also reported that higher cord blood 25(OH)D concentrations were associated with decreased risk of early childhood eczema. Another possible limitation to the generalisability of our results was that we had a predominance of Caucasian mothers (95\%). Since Caucasian mothers were found to have higher cord blood 25(OH)D concentrations compared to non-Caucasian mothers, replication of our investigations would be beneficial in study populations with a predominance of non-Caucasian participants.

There are several randomised controlled trials currently investigating the effect of maternal vitamin D supplementation during pregnancy on allergic disease outcomes (NCT00920621 and NCT00856947). The level of supplementation tested in these trials should be adequate to attain a significant shift in maternal 25(OH)D levels and therefore provide definitive evidence regarding the effect of vitamin D during pregnancy on early childhood allergic disease.

\section{Conclusion}

In children with a family history of allergic disease, higher cord blood 25(OH)D concentrations appear to be associated with a reduction in the risk of eczema development through to 3 years of age.

\section{Abbreviations}

25(OH)D: 25-hydroxyvitamin D; DHA: Docosahexaenoic Acid; DOMInO: Docosahexaenoic acid to Optimise Mother Infant Outcome; IgE: Immunoglobulin E.

\section{Competing interests}

The authors declare that they have no competing interests.

\section{Authors' contributions}

Study conception and design (all authors), acquisition of data (DP, MM, TS), analysis and interpretation of data (all), drafting of the manuscript (DP, MM, TS), critical revision of the manuscript (all), obtained funding (MM, DP, LS) and study supervision (DP, MM). All authors read and approved the final manuscript.

\section{Author details}

${ }^{1}$ Women's \& Children's Health Research Institute, University of Adelaide, North Adelaide, SA 5006, Australia. ${ }^{2}$ School of Paediatrics and Child Health, University of Western Australia, Subiaco, WA 6008, Australia. ${ }^{3}$ School of Population Health, University of Adelaide, Adelaide, SA 5005, Australia. ${ }^{4}$ Department of Human Nutrition, University of Otago, Dunedin 9054, New Zealand. ${ }^{5}$ Healthy Mothers, Babies and Children, South Australian Health and Medical Research Institute, Adelaide, SA 5000, Australia. ${ }^{6}$ School of Paediatrics and Reproductive Health, University of Adelaide, Adelaide, SA 5005, Australia. 
Received: 12 May 2015 Accepted: 30 July 2015

Published online: 06 October 2015

\section{References}

1. Miyake Y, Sasaki S, Tanaka K, Hirota Y. Dairy food, calcium and vitamin D intake in pregnancy, and wheeze and eczema in infants. Eur Respir J. 2010;35:1228-34

2. Nwaru BI, Ahonen S, Kaila M, Erkkola M, Haapala AM, Kronberg-Kippila C, et al. Maternal diet during pregnancy and allergic sensitization in the offspring by 5 yrs of age: a prospective cohort study. Pediatr Allergy Immunol. 2010;21:29-37.

3. Erkkola M, Kaila M, Nwaru BI, Kronberg-Kippila C, Ahonen S, Nevalainen J, et al. Maternal vitamin $D$ intake during pregnancy is inversely associated with asthma and allergic rhinitis in 5-year-old children. Clin Exp Allergy. 2009:39:875-82

4. Baiz N, Dargent-Molina P, Wark JD, Souberbielle JC, Annesi-Maesano I, Group EM-CCS. Cord serum 25-hydroxyvitamin D and risk of early childhood transient wheezing and atopic dermatitis. J Allergy Clin Immunol. 2014;133:147-53.

5. Camargo Jr CA, Ingham T, Wickens K, Capelli A, Dondi E, Gatto M, et al. Cord-blood 25-hydroxyvitamin D levels and risk of respiratory infection, wheezing, and asthma. Pediatrics. 2011;127:e180-7.

6. Jones AP, Palmer D, Zhang G, Prescott SL. Cord blood 25-hydroxyvitamin D3 and allergic disease during infancy. Pediatrics. 2012;130:e1128-35.

7. Lai JK, Lucas RM, Clements MS, Harrison SL, Banks E. Assessing vitamin D status: pitfalls for the unwary. Mol Nutr Food Res. 2010;54:1062-71.

8. Paxton GA, Teale GR, Nowson CA, Mason RS, McGrath JJ, Thompson MJ, et al. Vitamin $D$ and health in pregnancy, infants, children and adolescents in Australia and New Zealand: a position statement. MJA. 2013;198:142-3.

9. Abrams SA, Coss-Bu JA, Tiosano D. Vitamin D: effects on childhood health and disease. Nat Rev Endocrinol. 2013;9:162-70.

10. Salle BL, Delvin EE, Lapillonne A, Bishop NJ, Glorieux FH. Perinatal Metabolism of Vitamin D. Amer J Clin Nutr. 2000;71:1317S-24.

11. Cadario F, Savastio S, Pozzi E, Capelli A, Dondi E, Gatto M, et al. Vitamin D status in cord blood and newborns: ethnic differences. Ital J Pediatrics. 2013;39:35.

12. Heckmatt JZ, Peacock M, Davies AE, McMurray J, Isherwood DM. Plasma 25-hydroxyvitamin $D$ in pregnant Asian women and their babies. Lancet. 1979:2:546-8.

13. Grant CC, Stewart AW, Scragg R, Hulsey TC, Ebeling M, Robinson C, et al. Vitamin D during pregnancy and infancy and infant serum 25hydroxyvitamin d concentration. Pediatrics. 2014;133:e143-53.

14. Wagner $C L$, McNeil RB, Johnson DD, Hulsey TC, Ebeling M, Robinson C, et al. Health characteristics and outcomes of two randomized vitamin D supplementation trials during pregnancy: a combined analysis. J Steroid Biochem Mol Biol. 2013;136:313-20.

15. Weisse K, Winkler S, Hirche F, Herberth G, Hinz D, Bauer M, et al. Maternal and newborn vitamin $D$ status and its impact on food allergy development in the German LINA cohort study. Allergy. 2013;68:220-8.

16. Makrides M, Gibson RA, McPhee AJ, Yelland L, Quinlivan J, Ryan P. Effect of DHA supplementation during pregnancy on maternal depression and neurodevelopment of young children: a randomized controlled trial. JAMA. 2010;304:1675-83.

17. Palmer DJ, Sullivan T, Gold MS, Prescott SL, Heddle R, Gibson RA, et al. Effect of n-3 long chain polyunsaturated fatty acid supplementation in pregnancy on infants' allergies in first year of life: randomised controlled trial. BMJ. 2012;344:e184.

18. Palmer DJ, Sullivan T, Gold MS, Prescott SL, Heddle R, Gibson RA, et al. Randomized controlled trial of fish oil supplementation in pregnancy on childhood allergies. Allergy. 2013;68:1370-6.

19. Maunsell Z, Wright DJ, Rainbow SJ. Routine isotope-dilution liquid chromatography-tandem mass spectrometry assay for simultaneous measurement of the 25-hydroxy metabolites of vitamins D2 and D3. Clin Chem. 2005:51:1683-90.

20. Hanifin JM, Rajka G. Diagnostic features of atopic dermatitis. Acta Dermatovener. 1980;92:44-7.

21. Jenab M, Bueno-de-Mesquita HB, Ferrari $P$, van Duijnhoven FJ, Norat $T$, Pischon $T$, et al. Association between pre-diagnostic circulating vitamin $D$ concentration and risk of colorectal cancer in European populations:a nested case-control study. BMJ. 2010;340:b5500.

22. Nurmatov U, Nwaru Bl, Devereux G, Sheikh A. Confounding and effect modification in studies of diet and childhood asthma and allergies. Allergy. 2012;67(8):1041-59.
23. Kapoor R, Menon C, Hoffstad O, Bilker W, Leclerc P, Margolis DJ. The prevalence of atopic triad in children with physician-confirmed atopic dermatitis. J Am Acad Dermatol. 2008;58:68-73.

24. Chawes BL, Bonnelykke K, Jensen PF, Schoos AM, Heickendorff L, Bisgaard H. Cord blood 25(OH)-vitamin D deficiency and childhood asthma, allergy and eczema: the COPSAC2000 birth cohort study. PLoS One. 2014;9:e99856.

25. Goldring ST, Griffiths CJ, Martineau AR, Robinson S, Yu C, Poulton S, et al. Prenatal vitamin D supplementation and child respiratory health: a randomised controlled trial. PLoS One. 2013;8:e66627.

26. Rothers J, Wright AL, Stern DA, Halonen M, Camargo Jr CA. Cord blood 25-hydroxyvitamin D levels are associated with aeroallergen sensitization in children from Tucson, Arizona. J Allergy Clin Immunol. 2011;128:1093-9. e1-5.

27. Sugarman JL. The epidermal barrier in atopic dermatitis. Semin Cutan Med Surg. 2008;27:108-14.

28. Bikle DD. Vitamin D, metabolism and function in the skin. Mol Cell Endocrinol. 2011:347:80-9.

29. Wang $S S$, Hon $K L$, Kong AP, Pong HN, Wong GW, Leung TF. Vitamin D deficiency is associated with diagnosis and severity of childhood atopic dermatitis. Pediatr Allergy Immunol. 2014;25:30-5.

30. Osborne NJ, Koplin JJ, Martin PE, Robinson S, Yu C, Poulton S, et al. Prevalence of challenge-proven lgE-mediated food allergy using populationbased sampling and predetermined challenge criteria in infants. J Allergy Clin Immunol. 2011;127:668-76. e1-2.

\section{Submit your next manuscript to BioMed Central and take full advantage of:}

- Convenient online submission

- Thorough peer review

- No space constraints or color figure charges

- Immediate publication on acceptance

- Inclusion in PubMed, CAS, Scopus and Google Scholar

- Research which is freely available for redistribution 